DOI: https://doi.org/10.15688/lc.jvolsu.2018.3.12

UDC 340.12

LBC 67.0

\title{
TO CONSTRUE CANNOT BE TO INTERPRET
}

\author{
Yulia A. Gavrilova \\ Volgograd State University, Volgograd, Russian Federation
}

\begin{abstract}
Introduction: it is necessary to analyze the existing trend in the legal literature to increase the distance between the main ways of understanding the meaning of law in the direction of the obvious "diminution" of the role of construction of law and expanding the scope of the use of the concept of interpretation. The purpose of the study is to determine the correlation of the concepts "construction" and "interpretation" used in modern Russian law. The objectives of the study are to formulate a number of conceptual problems: "construction", "interpretation", "concretization", "meaning", "meaning of law", as well as to reveal the cultural, historical and linguistic origins of the concepts "construction" and "interpretation". Methods: the article uses formal-legal, concrete-sociological and comparative law research methods. Results: the author proceeds from the etymology of the Russian word "construction" as understanding, reasonable understanding, the explanation of something already available. In this regard, interpretation in the domestic law is a creative moment of the process of construction of law, expressing the dynamism of the interpreter's thinking or the result of the correlation of the text and the meaning of the rule in the process of construction of law in volume. In contrast to the importance attached to these phenomena in foreign studies, the creation of a new meaning of the legal norm is not "interpretation", but a more complex legal phenomenon - "meaning formation". Conclusions: in summary, the author concludes that the distinction between the terms "construction" and "interpretation" is permissible only conditionally depending on different levels of conceptualization of the problem of the meaning of law: at the level of the problem of legal consciousness - the interpretation of law as its doctrinal construction, and at the level of the legislation and legal practice - construction (interpretation) to the extent of their confusion (identification), but not as a replacement of "construction" by "interpretation". In the context of modern global processes of the XXI century, the construction of law is an important tool to maintain the Russian legal identity, to preserve the developments and achievements of the national theory of law, in which the concept of construction has always been and continues to be of a key and fundamental importance.
\end{abstract}

Key words: construction, interpretation, specification, meaning-making, the meaning of law.

Citation. Gavrilova Yu.A. To Construe Cannot Be to Interpret. Legal Concept, 2018, vol. 17, no. 3, pp. 83-90. DOI: https://doi.org/10.15688/lc.jvolsu.2018.3.12

УДК 340.12

ББК 67.0

\section{ТОЛКОВАТЬ НЕЛЬЗЯ ИНТЕРПРЕТИРОВАТЬ}

\section{Юлия Александровна Гаврилова}

Волгоградский государственный университет, г. Волгоград, Российская Федерация

Введение: необходим анализ существующей в юридической литературе тенденции к увеличению дистанции между основными путями познания смысла права в сторону явного «умаления» роли толкования права и расширения сферы употребления понятия интерпретации. Цель исследования - определить соотношение понятий «толкование» и «интерпретация», употребляемых в современном российском праве. Задачи исследования - сформулировать понятийный ряд проблемы: «толкование», «интерпретация», «конкретизация», «смыслообразование», «смысл права», а также раскрыть культурно-исторические и языковые истоки образования понятий «толкование» и «интерпретация». Методы: в статье используются формально-юридический, конкретно-социологический и сравнительно-правовой методы исследования.

Результаты: автор исходит из этимологии русского слова «толкование» как понимания, разумного ос- 


\section{ТЕОРИЯ И ПРАКТИКА ГОСУДАРСТВЕННО-ПРАВОВОГО РАЗВИТИЯ}

мысления, объяснения чего-либо уже имеющегося. В этой связи интерпретация в отечественном праве это творческий момент процесса толкования права, выражающий динамизм мышления интерпретатора либо результат соотнесения текста и смысла нормы в процессе толкования права по объему. В отличие от значения, придаваемого этим явлениям в зарубежных исследованиях, создание нового смысла правовой нормы является не «интерпретацией», а более сложным по составу правовым феноменом - «смыслообразованием». Выводы: в заключение автор формулирует вывод о том, что разграничение терминов «толкование» и «интерпретация» допустимо лишь условно в зависимости от разных уровней концептуализации проблемы смысла права: на уровне проблемы правопонимания - интерпретация права как доктринальное его толкование, а на уровне законодательства и юридической практики - толкование (интерпретация) до степени их смешения (отождествления), но не в качестве замены «толкования» с помощью «интерпретации». В условиях современных глобализационных мировых процессов XXI в. толкование права является важнейшим инструментом поддержания российской правовой идентичности, сохранения наработок и достижений отечественной теории права, в рамках которой понятие толкования всегда имело и продолжает сохранять ключевое и фундаментальное значение.

Ключевые слова: толкование, интерпретация, конкретизация, смыслообразование, смысл права.

Цитирование. Гаврилова Ю. А. Толковать нельзя интерпретировать // Legal Concept = Правовая парадигма. - 2018. - Т. 17, № 3. - C. 83-90. - DOI: https://doi.org/10.15688/lc.jvolsu.2018.3.12

\section{Введение}

Любая наука рано или поздно проходит переломные этапы своего развития, когда ключевые понятия, уже прошедшие «огонь, воду и медные трубы», начинают подвергаться новому переосмыслению. Такая непростая историческая судьба постигла важнейшие в отечественной юриспруденции понятия толкования и интерпретации права. В современной юридической литературе нарастает тенденция, связанная с отказом от понятия толкования и стремлением к его поглощению и унификации использования как «интерпретации». Настоящая статья представляет собой полемический отклик на статью Е.М. Терехова, опубликованную в журнале «Legal Concept = Правовая парадигма» № 1 за 2018 год. В связи с тем, что некоторые аспекты этой темы освещались автором в монографиях и ряде публикаций по вопросам толкования права и смысла права, автор посчитал необходимым принять участие в актуальной терминологической дискуссии по этой проблеме.

\section{Этимологические и семантические аспекты эволюции терминов «толкование»и «интерпретация»}

Исходя из семантических оснований, русский термин «толкование» и латинский «интерпретация» являются синонимичными. Этимологически же термин «толкование» в русском языке означал действие, производное от существительного «толк»: 1) искать пользу, выгоду, прок в бытовых вопросах; 2) осмыслить, дать разумное объяснение, понимание чему-либо имеющемуся [7, с. 411-412]. Латинский термин «интерпретация» (по одной из версий) уходит корнями в исполнение судебных и военно-административных управленческих функций преторов, которые через издание эдиктов приспосабливали древнейшее право Законов XII таблиц (jus quiritium) к изменяющимся условиям жизни римского рабовладельческого общества. Наряду с нормами единого для римских жителей цивильного права (jus civile), такая совместная деятельность преторов (inter) способствовала формированию новых дополнительных источников права: «преторского права» (jus praetorium) и «права народов» (jus gentium), в результате чего была исторически именована как «интерпретация» $[9$, с. $155-156]$.

В дореволюционном русском правоведении поддерживалась отечественная языковая и культурная традиция использования термина «толкование», в основном сохранившаяся в советское время. Однако поскольку в советский период развития юридической науки считалось, что толкование не создает новый смысл права, наличие в правотворческой деятельности элементов конструктивной смысловой новизны замещалось термином «конкретизация» $[23$, с. 5]. При этом понятие интерпретации как бы ушло «в тень» и воспринималось на уровне доктринального правосознания как синоним толкования. 


\section{Философско-мировоззренческие предпосылки разграничения терминов \\ «толкование»и «интерпретация» в отечественной литературе}

Можно назвать две наиболее общие причины роста познавательного интереса к интерпретации.

1. С 90-х гг. ХХ в. в российское научное пространство «хлынул» поток публикаций из западной философии и общественных наук, в которых широко применялся термин «интерпретация». В исследованиях по семиотике, герменевтике, феноменологической и коммуникативной теориях с помощью этого термина описываются интеллектуальные приемы, направленные на понимание самых разнообразных текстов и внеязыковых (невербальных) феноменов: жестов, ритуалов, поведения и т. д., анализируются внутренний психический мир субъектов права и проблемы их взаимодействия в общем смысловом пространстве (дискурсе). Это не могло не сказаться на качестве научных изысканий в отечественном праве, стимулировав «интерпретационный» вектор работ и по вопросам плюрализма правопонимания, и по прикладным аспектам теории права. Отдельные ученые с разными целями активно вводят в оборот термин «интерпретация» $[2 ; 3 ; 12 ; 13 ; 22$ и др.]. Однако они понимают интерпретацию и в узком значении как толкование «имеющегося» смысла права, и в широком значении - как процесс познания права в режиме определенного плюрализма или актуальности, динамики понимания этого смысла. В этом, на наш взгляд, и состоит основной «камень преткновения» в научной дискуссии между сторонниками «толкования» или «интерпретации».

Думается, что наделение «интерпретации» какими-либо универсальными свойствами «смыслопорождения», «внесения элементов нормативной новизны» и т. п. не отвечает семантическому потенциалу русского слова «толкование» - «искать смысл». Этот взгляд является результатом заимствования из иностранной, прежде всего американской, доктрины толкования, где противоречие между текстуализмом (буквой закона) и оригинализмом (намерениями законодателя) преодолевается динамическим способом толкования, в качестве аналога которого и подразумевается использовать термин «интерпретация» в российском праве. Но это производится без учета российских традиций правопонимания, правовой культуры и менталитета. Более того, в отечественной доктрине существует самостоятельный путь решения проблемы, когда расхождение между текстом и смыслом нормы разрешается с помощью соответствующих приемов толкования права по объему: расширительного или ограничительного [5, c. 106-132].

При оценке герменевтических аспектов правовой интерпретации необходимо различать, по справедливому замечанию Р.А. Ромашова, «герменевтику как метатеорию или метафилософию права», - и с этим вполне можно согласиться как с интерпретацией права на уровне правопонимания, - и «герменевтику как систему конкретных формально-юридических приемов анализа правового текста», которые на уровне законодательства и юридической практики не могут выходить за пределы традиционного толкования [20, с. 87$]$.

2. В отечественном праве затянулась на несколько десятилетий теоретическая дискуссия о соотношении толкования и конкретизации права. Современное знание многоаспектно, разнородно и является дискуссионным. Изза этого попытки описать эти понятия в четких лаконичных определениях формальной логики чаще всего завершаются неудачей. И это связано с тем, что отсутствует однозначная понятийная матрица их обобщения, не имеется ясных критериев оценки этих феноменов, а выделяемые при этом большинством специалистов основные параметры сходства и различия толкования и конкретизации права имеют исходное спорное и недостаточно конкретное содержание.

Между тем выход из затруднительного положения, в котором оказалась теория права, многим ученым и юристам-практикам видится в своеобразной «реанимации» понятия интерпретации права как исторического проекта, в котором запрограммирована сама возможность операций с правовыми смыслами. В подтверждение сказанного интерпретация понимается как «установление воли законодателя, а также языковой анализ юридического текста с учетом историко-политических 


\section{ТЕОРИЯ И ПРАКТИКА ГОСУДАРСТВЕННО-ПРАВОВОГО РАЗВИТИЯ}

условий создания и действия нормы» $[16$, c. 68], «раскрытие содержания правового текста с выведением из него юридических конструкций» [21, с. 726], «разворачивание нормы права в действительности без изменения ее текста» $[14$, с. 559$]$ и т. д.

На наш взгляд, во всех названных случаях под единым термином «интерпретация» фактически отождествляются два разных понятия - «толкование» и «конкретизация». Дело в том, что исходным пунктом смыслообразования в праве всегда является толкование, дополняемое в дальнейшей практике с помощью усмотрения, аналогии, субсидиарного правоприменения и других правовых средств. Они усиливают или ослабляют регулятивный потенциал толкования и, действуя в сочетании с ним и друг с другом, вызывают эффект состоявшейся конкретизации-«актуализации» во времени, которая и приводит к модификации существующего или конструированию нового смысла действующего законодательства. Следовательно, объединение столь сложных и разнородных операций в рамках понятия «интерпретация» значительно нивелирует специфику последних и создает предпосылки для их рассмотрения в качестве своеобразных «придатков» или видов интерпретации, что по отношению к этому технико-юридическому инструментарию было бы несправедливо.

В этой связи следует скептически отнестись к позиции Е.М. Терехова, который различает правоинтерпретационную деятельность и толкование права вообще и Верховного суда Российской Федерации в частности. Различие между этими терминами строится, на наш взгляд, не в соответствии с правовым статусом субъекта толкования или его юридическими последствиями (официальное и неофициальное), а состоит в том, что динамизм мышления интерпретатора не всегда тождественен динамизму результатов его деятельности. Поэтому так нелегко порой бывает заключить, чем мы занимаемся в процессе познания смысла права: мы толкуем право или мы его интерпретируем.

Если динамизм мышления не выходит, по меткому выражению А.С. Пиголкина, «за пределы сознания интерпретатора» [15, с. 8-9], то интерпретация - это творческий аспект процесса толкования права, реализующий идею автономии и свободы суждений интерпретатора по уяснению смысла правовых велений, но в определенных пределах: пока они не формализуются в виде разъяснения и не получают внешнее выражение в соответствующем акте толкования [4, с. 453]. Интерпретация в этом случае полностью охватывается понятием толкования права.

Если же динамический компонент выходит за пределы мышления, то он объективируется в результатах практической деятельности интерпретатора, которые могут характеризоваться сравнительной новизной (абсолютной или относительной). При относительной новизне результатов, например, интерпретатор мог стремиться к совпадению текстуальной формулировки и действительного смысла нормативного предписания. Интерпретация в данной ситуации представляет собой сам процесс толкования права по объему. При наличии абсолютной смысловой новизны в понимании содержания действующего предписания такая деятельность выходит за пределы понятия толкования, но в отличие от значения, придаваемого ему в зарубежных исследованиях, является уже не «интерпретацией», а «смыслообразованием», в рамках которого совместное использование толкования и других правовых инструментов чаще всего приводит не только к обновлению, но и к созданию новых юридических смыслов.

\section{Теоретико-методологические основания использования термина «интерпретация» в зарубежной литературе}

Современные взгляды на соотношение толкования и интерпретации формируются на пересечении философских, политических и конституционно-правовых проблем. В частности, идеи представителей зарубежной герменевтики можно оценить в контексте соответствующих типов научной рациональности: классики, неклассики и постнеклассики [24, c. $35 ; 11$, c. 17,24$]$.

Например, итальянский юрист и философ Э. Бетти придерживался классического подхода к толкованию, согласно которому внутренние намерения законодателя как автора всегда находят внешнее выражение в юриди- 
ческом тексте закона. Это поле преимущественно психологической, субъективно ориентированной интерпретации, где автор выделил четыре основополагающих принципа (канона) герменевтической интерпретации: во-первых, «автономия объекта интерпретации», во-вторых, «целостность или смысловая связность этого объекта», в-третьих, канон «актуальности понимания» и, наконец, в-четвертых, принцип «смыслового соответствия или смысловой адекватности понимания» [1, с. 22-27, 29, 32, 33, 40, 117-119].

В отличие от Э. Бетти, Г.Х. Гадамер разделял неклассические представления о толковании, в соответствии с которыми не важно, что хотел сказать автор (законодатель), главное - то, что написано в самом тексте закона и что нам говорят об этом языковые знаки и символы («объективный смысл текста» или «объективная воля закона»). «...Мы можем считать общим для всех форм герменевтики следующее: подлежащий пониманию текст обретает конкретность и завершенность лишь в истолковании, и тем не менее это последнее крепко держится за смысл самого текста» $[6$, с. 391].

Неклассическая позиция П. Рикера характеризуется дуализмом. Он различал «толкование» по отношению к языку как «закрытому универсуму знаков, соотносящихся друг с другом значениями (тексту)», и «интерпретацию» бытия человека и его сознания, которые он воспринимал как «открытый универсум, работающий в режиме раскрытия смыслов» и подлежащий уже неограниченной трактовке [19, с. 104].

Постнеклассический или постмодернистский подход к толкованию окончательно смещает его целевые ориентиры с автора и самого текста на интерпретатора (читателя). Отказ от идеи обусловленности интерпретации каким-либо критерием правильности или адекватности, то есть отсутствие «нормы» интерпретации, и отсутствие первоначальной структурной упорядоченности познавательной информации в сознании интерпретатора означают, что процесс интерпретации - это создание каждый раз нового текста с новым смыслом. Об этом свидетельствует терминологический аппарат исследований: «децентрированное смысловое поле», «означивающая про- дуктивность» и «значащая структура» и пр. [8, c. $354 ; 10$, с. 294].

Вместе с тем в юридических отношениях центр часто необходим, чтобы люди могли договариваться, например, об общем понимании тех или иных ценностных идей в судебной практике. И, перефразируя старую мудрость, жить в определенном социально-историческом контексте действия права и быть свободным от этого контекста в процессе толкования права невозможно. Именно в этом ключе в современном российском праве начали формироваться элементы концепции «динамической корректировки Конституции Российской Федерации» [17].

\section{Выводы}

1. Смысл права является единым понятием, сочетающим стабильные и динамические компоненты. Из этого следует, что искусственно противопоставлять семантически сходные термины «толкование» и «интерпретация» по этому основанию вряд ли целесообразно, поскольку «интерпретация» - это всетаки момент толкования либо явление, совпадающее с процессом толкования по объему. Напротив, разграничение по данному основанию семантически различных терминов «толкование» и «конкретизация» имеет свои предпосылки, но это является уже предметом отдельного обсуждения.

2. На уровне проблемы правопонимания термин «интерпретация» вполне может использоваться самостоятельно в значении доктринального толкования для построения общенационального образа смысла права. На уровне же законодательства и юридической практики термин «интерпретация», как показывает судебная практика [18], должен использоваться параллельно с «толкованием» до степени смешения (отождествления), но не как альтернативная его замена. В противном случае каждый субъект может под видом интерпретации выдавать созданный им в процессе правопонимания субъективный смысл права в целом за объективный смысл конкретных норм законодательства или правоположений юридической практики и на этом основании утверждать в постмодернистском духе, что его субъективный образ права - это и есть «истинное» право, что в условиях российской 


\section{ТЕОРИЯ И ПРАКТИКА ГОСУДАРСТВЕННО-ПРАВОВОГО РАЗВИТИЯ}

правовой действительности нельзя признать правильным.

3. В условиях глобализационных мировых процессов XXI в. толкование права является важнейшим инструментом поддержания российской правовой идентичности, сохранения наработок и достижений отечественной теории права, в рамках которой понятие толкования всегда имело и продолжает сохранять ключевое и фундаментальное значение.

\section{СПИСОК ЛИТЕРАТУРЫ}

1. Бетти, Э. Герменевтика как общая методология наук о духе / Э. Бетти. - М. : Канон+ РООИ «Реабилитация», 2011.- 144 с.

2. Варламова, Н. В. Типология правопонимания и современные тенденции развития теории права / Н. В. Варламова. - М. : ГУВШЭ : ИГПРАН, 2010. $-136 \mathrm{c}$.

3. Веденеев, Ю. А. Интерпретации права как культурно-исторический феномен: категория и институт / Ю. А. Веденеев // Актуальные проблемы российского права. - 2016. - № 5. - С. 32-46.

4. Вопленко, Н. Н. Очерки общей теории права : монография / Н. Н. Вопленко. - Волгоград : Изд-во ВолГУ, 2009. - 898 с.

5. Гаврилова, Ю. А. Толкование права по объему : дис. ... канд. юрид. наук / Гаврилова Юлия Александровна. - Саратов, 2008. - 210 c.

6. Гадамер, Г. Г. Истина и метод: основы философской герменевтики / Г. Г. Гадамер ; общ. ред. и вступ. ст. Б. Н. Бессонова. - М. : Прогресс, 1988. - 704 с.

7. Даль, В. Толковый словарь живого великорусского языка. В 4 т. Т. 4 / В. Даль. - М. ; СПб. : Издание книгопродавца-типографа М. О. Вольфа, 1882. -683 с.

8. Деррида, Ж. Письмо и различие / Ж. Деррида. -СПб. : Академический проект, 2000. -430 с.

9. История государства и права зарубежных стран: учебник для студентов юридических вузов и факультетов. В 2 ч. Ч. 1 / под общ. ред. О. А. Жидкова, Н. А. Крашенинниковой. - М. : ИНФРА-М : HOPMA, 1997. $-480 \mathrm{c}$.

10. Кристева, Ю. Избранные труды: Разрушение поэтики / Ю. Кристева. - М. : Российская политическая энциклопедия (РОССПЭН), 2004. - 656 c. (Серия «Книга света»).

11. Лазарев, В. В. Толкование права: классика, модерн и постмодерн / В. В. Лазарев // Журнал российского права. - 2016. - № 8. - С. 15-28.

12. Малиновская, Н. В. Интерпретация в праве: генезис, эволюция, актуализация : дис. ... канд. юрид. наук / Малиновская Наталья Владимировна. M., 2010.-216 c.
13. Нарутто, С. В. Конкуренция конституционных прав и свобод человека в интерпретациях Конституционного суда Российской Федерации / С. В. Нарутто // Конституционное и муниципальное право. - 2010. - № 2. - С. 56-65.

14. Павлов, В. И. Судебное правотворчество в контексте теории интерпретации и антропологической концепции права / В. И. Павлов, Н. М. Дубрава // Юридическая техника. - 2014. - № 8. - С. 553-559.

15. Пиголкин, А. С. Толкование нормативных актов в СССР / А. С. Пиголкин. - М. : Госюриздат, 1962. $-166 \mathrm{c}$.

16. Пишина, С. Г. О методологической основе способов юридической интерпретации / С. Г. Пишина // Юридическая наука и практика: Вестник Нижегородской академии МВД России. - 2011. № 2. - С. 65-68.

17. Постановление Конституционного Суда Российской Федерации «По делу о проверке конституционности отдельных положений Федерального закона "Об общих принципах организации законодательных (представительных) и исполнительных органов государственной власти субъектов Российской Федерации" в связи с жалобами ряда граждан» от 21 дек. 2005 г. № 13-П // Собрание законодательства РФ. - 2006. - № 3. - Ст. 336.

18. Решение Верховного суда Российской Федерации ог 27 нояб. 2017 г. по делу № АКПИ17-892. Доступ из справ.-правовой системы «КонсультантПлюс».

19. Рикер, П. Конфликт интерпретаций. Очерки о герменевтике / П. Рикер ; пер. с фр. и вступит. ст. И. Вдовиной. - М. : Канон-Пресс-Ц : Кучково поле, 2002. $-624 \mathrm{c}$.

20. Ромашов, Р. А. Интернет - правовая среда герменевтики / Р. А. Ромашов // Ленинградский юридический журнал. - 2016. - № 4. - С. 84-96.

21. Сорокина, Ю. В. Юридическая конструкция как результат правовой интерпретации / Ю. В. Сорокина, Н. В. Малиновская // Юридическая техника. - 2013. - № 7 (ч. 2). - С. 721-726.

22. Степанов, С. А. Интерпретация интерпретации / С. А. Степанов // Российский юридический журнал. - 2017. - № 6. - С. 23-33.

23. Ткачева, С. Г. Конкретизация закона и его судебное толкование : автореф. дис. ... канд. юрид. наук / Ткачева Светлана Георгиевна. - М., 1973. - 20 с.

24. Хабриева, Т. Я. Доктринальное значение российской Конституции / Т. Я. Хабриева // Журнал российского права. - 2009. - № 2. - С. 34-38.

\section{REFERENCES}

1. Betti E. Germenevtika kak obshchaya metodologiya nauk o dukhe [Hermeneutics as a 
General Methodology of the Science of Spirit]. Moscow, Kanon+ ROOI Reabilitaciya Publ., 2011. 144 p.

2. Varlamova N.V. Tipologiya pravoponimaniya $i$ sovremennye tendentsii razvitiya teorii prava [Typology of Legal Understanding and Modern Trends in the Development of the Theory of Law]. Moscow, GUVSHE; IGPRAN Publ., 2010. 136 p.

3. Vedeneev Yu.A. Interpretatsii prava kak kulturno-istoricheskiy fenomen: kategoriya i institut [Interpretations of Law as a Cultural and Historical Phenomenon: Category and Institution]. Aktualnye problemy rossiyskogo prava, 2016, no. 5, pp. 32-46.

4. Voplenko N.N. Ocherki obshchey teorii prav: monografiya [Essays on the General Theory of Law. Monograph]. Volgograd, Izd-vo VolGU, 2009. 898 p.

5. Gavrilova Yu.A. Tolkovanie prava po obyemu: dis. ... kand. yurid. nauk [Interpretation of Law Volume. Cand. jurid. sci. diss.]. Saratov, 2008. 210 p.

6. Gadamer G.G. Istina i metod: osnovy filosofskoy germenevtiki [Truth and Method: the Foundations of Philosophical Hermeneutics]. Moscow, Progress Publ., 1988. 704 p.

7. Dal V. Tolkovyy slovar zhivogo velikorusskogo yazyka. V 4 t. T. 4 [Explanatory Dictionary of the Living Great Russian Language. In 4 vols. Vol. 1]. Moscow; Saint Petersburg, Izdanie knigoprodavtsa-tipografa M. O. Volfa, 1882. 683 p.

8. Derrida J. Pismo i razlichie [Writing and Distinction]. Saint Petersburg, Akademicheskiy proekt Publ., 2000. 430 p.

9. Zhidkov O.A., Krasheninnikova N.A., eds. Istoriya gosudarstva i prava zarubezhnykh stran. V 2 ch. Ch. 1 [History of the State and Law of Foreign Countries. In 2 parts. Part 1]. Moscow, INFRA-M; NORMA Publ., 1997. 480 p.

10. Kristeva Yu. Izbrannye trudy: Razrushenie poetiki [Selected Works: Destruction of Poetics]. Moscow, ROSSPEN Publ., 2004. 656 p.

11. Lazarev V.V. Tolkovanie prava: klassika, modern i postmodern [Interpretation of Law: Classics, Modern and Postmodern]. Zhurnal rossiyskogo prava, 2016, no. 8, pp. 15-28.

12. Malinovskaya N.V. Interpretatsiya $v$ prave: genezis, evolyutsiya, aktualizatsiya: dis. ... kand. yurid. nauk [Interpretation in Law: Genesis, Evolution, Actualization. Dis. ... cand. jurid. nauk]. Moscow, 2010. $216 \mathrm{p}$.

13. Narutto S.V. Konkurentsiya konstitutsionnykh prav i svobod cheloveka $\mathrm{v}$ interpretatsiyakh Konstitutsionnogo suda Rossiyskoy Federatsii [Competition of Constitutional Human Rights and Freedoms in the Interpretations of the Constitutional Court of the Russian Federation]. Konstitutsionnoe $i$ munitsipalnoe pravo, 2010, no. 2, pp. 56-65.

14. Pavlov V.I., Dubrava N.M. Sudebnoe pravotvorchestvo $\mathrm{v}$ kontekste teorii interpretatsii i antropologicheskoy kontseptsii prava [Judicial Lawmaking in the Context of the Theory of Interpretation and Anthropological Conception of Law]. Yuridicheskaya tekhnika, 2014, no. 8, pp. 553-559.

15. Pigolkin A.S. Tolkovanie normativnyh aktov $v$ SSSR [Interpretation of Regulatory Acts in the USSR]. Moscow, Yurlit Publ., 1962. 166 p.

16. Pishina S.G. O metodologicheskoy osnove sposobov yuridicheskoy interpretatsii [On the Methodological Basis of Legal Interpretation Methods]. Yuridicheskaya nauka i praktika: Vestnik Nizhegorodskoy akademii MVD Rossii, 2011, no. 2, pp. 65-68.

17. Postanovlenie Konstitutsionnogo Suda Rossiyskoy Federatsii «Po delu o proverke konstitutsionnosti otdelnykh polozheniy Federalnogo zakona "Ob obshchikh printsipakh organizatsii zakonodatelnykh (predstavitelnykh) i ispolnitelnykh organov gosudarstvennoy vlasti subyektov Rossiyskoy Federatsii" v svyazi s zhalobami ryada grazhdan» ot 21 dek. 2005 g. № 13-P [Decision of the Constitutional Court of the Russian Federation 'On the Case of Verifying the Constitutionality of Certain Provisions of the Federal Law "On General Principles for the Organization of Legislative (Representative) and Executive Bodies of State Power of the Subjects of the Russian Federation" in Connection with Complaints from a Number of Citizens' of 21 December 2005 No. 13P]. Sobranie zakonodatelstva RF [Collected Legislation of the Russian Federation], 2006, no. 3, art. 336.

18. Reshenie Verkhovnogo suda Rossiyskoy Federatsii ot 27 noyab. 2017 g. po delu № AKPI17-892 [Decision of the Supreme Court of the Russian Federation of 27 November 2017 on Case No. AKPI17-892]. Access from Reference Legal System 'Consultant Plus'.

19. Riker P. Konflikt interpretatsiy. Ocherki o germenevtike [Conflict of Interpretations. Essays on Hermeneutics]. Moscow, Kanon-Press-C; Kuchkovo pole Publ., 2002. 624 p.

20. Romashov R.A. Internet - pravovaya sreda germenevtiki [Internet is the Legal Environment of Hermeneutics]. Leningradskiy yuridicheskiy zhurnal, 2016, no. 4, pp. 84-96.

21. Sorokina Yu.V., Malinovskaya N.V. Yuridicheskaya konstruktsiya kak rezultat pravovoy interpretatsii [Legal Construction as a Result of Legal Interpretation]. Yuridicheskaya tekhnika, 2013, no. 7 (part 2), pp. 721-726.

22. Stepanov S.A. Interpretatsiya interpretatsii [Interpretation of Interpretation]. Rossiyskiy yuridicheskiy zhurnal, 2017, no. 6, pp. 23-33.

23. Tkacheva S.G. Konkretizatsiya zakona i ego sudebnoe tolkovanie: avtoref. dis. ... kand. yurid. nauk [Concretization of Law and Its Judicial Interpretation. Cand. jurid. sci. abs. diss.]. Moscow, $1973.20 \mathrm{p}$. 


\section{ТЕОРИЯ И ПРАКТИКА ГОСУДАРСТВЕННО-ПРАВОВОГО РАЗВИТИЯ}

24. Khabrieva T.Ya. Doktrinalnoe znachenie rossiyskoy Konstitutsii [The Doctrinal Significance of the Russian Constitution]. Zhurnal rossiyskogo prava, 2009, no. 2, pp. 34-38.

\section{Information about the Author}

Yuliya A. Gavrilova, Candidate of Sciences (Jurisprudence), Associate Professor, Department of Theory and History of Law and State, Volgograd State University, Prosp. Universitetsky, 100, 400062 Volgograd, Russian Federation, gavrilova_ua@volsu.ru.

\section{Информация об авторе}

Юлия Александровна Гаврилова, кандидат юридических наук, доцент кафедры теории и истории права и государства, Волгоградский государственный университет, просп. Университетский, 100, 400062 г. Волгоград, Российская Федерация, gavrilova_ua@volsu.ru. 